\title{
Selecting a Robust Decision Making Method to Evaluate Employee Performance
}

\author{
Haddad M., Sanders D. and Bausch N.
}

\begin{abstract}
This paper investigates how to select a robust decision making method to evaluate employee performance. Two Multiple Criteria Decision Making (MCDM) methods are considered for the evaluation of U.S. Coast Guard officers. Sensitivity analysis is conducted to understand the nature of uncertainty in evaluation criteria and employee performance. Outcomes from this analysis provide an understanding of the most critical factors governing the evaluation. MCDM methods dealing with discrete sets of alternatives are considered. The stability of two MCDM methods' outcomes are compared and the method with the most stable outcome is recommended. The minimum percentage change in criteria weights and performance scores required to alter the outcome of the evaluation is calculated. A MCDM method is recommended based on a best compromise in minimum percentage change required in inputs to alter the outcome of a method.
\end{abstract}

Keywords: Employee performance, Decision making, Evaluation, Sensitivity, Stability.

\section{Introduction}

Increased interest in Human Resource Management (HRM) has led to the development of different theories and approaches for staff evaluation. These theories and approaches enhanced organizations' performance and success (Saridakis et al, 2017). But different performance evaluation methods often produce different results (Haddad \& Sanders, 2018). The aim of this paper is to create a robust and fair model for employee evaluation. This problem can be considered to be a multiple criteria decision making (MCDM) problem with several evaluation criteria, as an example of how to select a robust method, two MCDM methods were applied to the evaluation of US Coast guard officers and the most stable outcome was adopted.

Sensitivity analysis was conducted on the outcomes of the two MCDM methods to focus on uncertainty in the function and processes of HRM. This is a new way of dealing with uncertainties in evaluation criteria and employee performance. An employee evaluation problem from Expert Choice Sample Models was used as an example in this paper (Expert Choice, 2013). The aim was to evaluate the performance of US Coast Guard officers.

Human resources represent an important factor in achieving success (Bella et al, 2018). Many researchers claimed that there is a positive correlation between HRM practices and organization performance (Renkema et al, 2017; Saridakis et al, 2017). HRM processes are highly affected by an Organization type, ranging from hardest in functional organizations to effective in projectized (PMBOK, 2004).

Employee evaluation is often considered as a complex task that considers various aspects and evaluation criteria. Moreover, employees often work on different projects and their overall performance is an aggregation of individual performance in the projects they participated in (Lidinska \& Jablonsky, 2018). 
Lidinska and Jablonsky (2018) described four main areas of a performance management framework: Evaluation criteria; Evaluation frequency; Criteria weights; and Rating system proposal. In this paper the criteria weights and the selection of the rating system are considered.

The impact of the method on actual decisions is well known, as well as the consequences of poor decisions (Kornyshova \& Salinesi, 2007). Eldarandaly et al, (2009) asserted that applying different MCDM methods to the same problem could often generate different outcomes. The use of an inappropriate MCDM method could therefore lead to inappropriate decisions (Ozernoy, 1992). Ishizaka and Siraj (2018) asserted the importance of good decisions and claimed that several MCDM methods were improving them.

\section{MCDM Methods}

Antoniou and Aretoulis (2018) traced MCDM methods back to 1738 when Daniel Bernoulli (1700 1782) published the utility theory that addressed the decision making process based on the utility theory of an alternative rather than the expected utility of the alternative.

Wang et al (2010) regards MCDM as a branch of Operational Research (OR) that is useful for some complicated problems within risky or uncertain situations such as evaluating employee performance. Eyvindson et al (2018) described them as mathematical methods used to find a best compromise solution based on judgments provided by stakeholders. For two decades, MCDM has been one of the fastest emerging areas within OR. It has been used to sort alternatives into pre-defined groups, to rank alternatives, to select best fits, and to describe problems (Roy, 1985). MCDM methods can handle conflicting criteria to tackle complex problems in business, engineering, management, science and other applications (Maleki \& Zahir, 2013). Haddad et al (2018, 2019) said that MCDM methods help decision makers to understand their problems and the factors that might influence the problems in an attempt to produce "Good" enough solutions.

Durbach and Stewart (2012) claimed that all multi-criteria methods improved decision making. That is achieved by decomposing assessment of the alternatives into a number of possibly conflicting criteria. It can be challenging to test MCDM methods to see how accurate they are because they use different methods and are difficult to compare (Olson et al, 2007). MCDM methods perform more efficiently for particular types of problems (Razmak and Aouni, 2015). MCDM is sequential although a user can go through a number of iterations in an attempt to produce a robust solution. Being able to check on the consistency of the comparisons made could be important.

Human judgment is prone to error and bias, and Comes et al (2013) identified some noticeable biases: Confirmation bias; Anchoring bias; Availability bias. Human behaviour is a source of inconsistency, but it is not the only one. Decision makers cab describe alternatives and criteria on scales with limited sets of numbers so that digitisation errors appear, and the measurement scales used for different methods can provide some inconsistency (Haddad et al, 2018).

Managers and human resources staff need to appreciate potential uncertainty to improve the decisions they make about employees and reduce risk. Moreover, understanding of uncertainty could lower inconsistency rates and lead to more reliable and robust representations of weights and performance evaluation scores (Haddad et al, 2018; Norese, 2016). Scholten et al (2015) claimed that uncertainty in criteria weights could be present because of bias, inaccurate quantitative estimates, or because of the 
use of inexact weights. Under-rating uncertainty can have an adverse effect on long-term planning because the costs of making a wrong decision can be significant.

Haddad et al (2018) said there is not a perfect MCDM method. Decision-makers may not be able to provide all the information and different problems will need different algorithms to produce suitable outcomes. They also said that performance evaluation scores and criteria weights are often hard to describe as "exact" numbers in real life. They presented examples where criteria values could not be defined as exact numbers and instead, modelled criterion weight uncertainty as fuzzy values and probability functions. They said inaccuracy could be understood more by using pseudo criteria; introducing indifference and preference thresholds so that inaccuracy might be filtered out between them.

Sensitivity analysis should be performed to validate the feasibility and to check the robustness of MCDM solutions (Saaty \& Ergu, 2015). Danesh et al (2018) mentioned that sensitivity analysis should be considered as an important factor of quantitative decision models since it shows the strengths and weaknesses of the models. Saltelli et al (2000) defined sensitivity analysis as the analysis of the effect of uncertainty in the output of a model, affected by uncertainty in its inputs. Haddad et al (2018) suggested that it is best to conduct sensitivity analysis on both the performance scores and the criteria weights. Sun et al (2011) said that robustness is an indicator of the ability of a system to tolerate uncontrollable changes in inputs.

Three types of sensitivity analysis were defined by Wolters and Mareschal (1995) for problems:

- The effect of changes in performance scores of one alternative with respect to a criterion.

- Sensitivity of a ranking to changes in scores of all alternatives depending on a certain criterion. In this case uncertainties are in particular criterion scores.

- The minimum change in criteria weights required to make an alternative ranked first.

Haddad (2017) identified the following steps to reach a most suitable (best compromise) solution in any multi-criteria problem: Identify the problem; Define goals and targets; Define a set of criteria; Identify alternatives; Select a MCDM method to evaluate the overall score of alternatives with respect to the criteria set; and Review and evaluate outcomes. The decision process can be iterative and at the end of the process, decisions may need to be reviewed and then validated. Ineffective, failed or unsuitable decisions need to be reconsidered before restarting the process.

Because they are often uncertain and ambiguous and can involve a large number of stakeholders with varying preferences, HRM decisions can be difficult to make (Comes et al, 2013). Figure 1 shows the 4 stage model of the decision-making process created by Grechuk and Zabarankin (2018). It also considered uncertainty. Grechuk and Zabarankin (2018) said that analysts and decision makers have experimental and historical data, which is not sufficient. Data from a better statistical understanding of the assumptions might give a better understanding of the uncertainty and risk that are connected to the

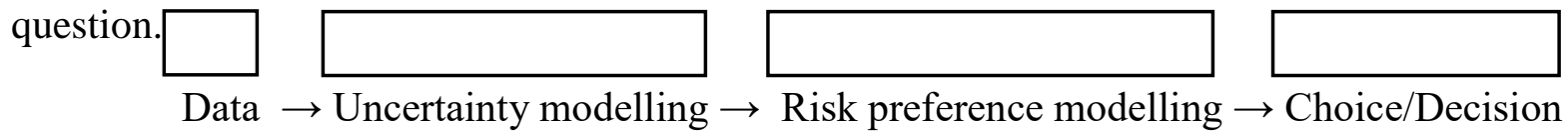

Figure 1: The four stage model of decision-making by Grechuk and Zabarankin (2018)

Eldarandaly et al (2009) said that applying different MCDM methods to the same problem could often generate different outcomes. Using an unsuitable MCDM method can lead to poor decisions (Haddad et al, 2018). Ishizaka and Siraj (2018) stated the significance of making good decisions and said that MCDM was improving them. 
Many researchers considered HRM decisions as multi criteria decisions. Mammadova and Jabrayilova (2015) considered the HRM decisions as a fuzzy MCDM problem, and they proposed the use a modified TOPSIS method to ensure adaptability in HRM decisions. They applied their proposed methodology in the HRM department of the State Oil Company of the Azerbaijan Republic for proper evaluation of the applicants. Lidinska and Jablonsky (2018) applied AHP to produce a fair and simple employee evaluation process in one of the middle-size management consulting companies operating in the Czech Republic. This company provided consulting and financial advisory services to public and private clients and employed around 300 consultants.

As an example, this paper will apply two popular MCDM methods to HRM evaluation decisions: AHP and PROMETHEE II. The stability of the outcomes of these methods will be compared in the presence of uncertainty in evaluations criteria weights and employee performance scores, and the method that delivered the most stable outcome will be recommended. The MCDM methods used were based on different approaches. AHP is based on pairwise comparison between the alternatives while PROMETHEE II is based on outranking relations among alternatives. The next two sub-sections give a brief explanation of the MCDM methods used.

\section{a. The Analytical Hierarchy Process (AHP)}

AHP is a MCDM method developed by Thomas L. Saaty in 1971- 1975 (Saaty, 1987). AHP helps decision makers to solve a problem with multiple conflicting subjective criteria (Ishizaka \& Labib 2009) by breaking down a complex problem into simpler sub-problems then, aggregating the solutions of all sub-problems into one solution (Saaty, 1994). AHP uses expert judgments to derive priorities and apply pairwise comparisons to measure how much one alternative dominates another with respect to a certain criterion (Saaty, 2008). Using a hierarchical structure of the criteria, AHP could allow users to focus on specific criteria and sub-criteria when providing judgments. Figure 2 shows a simple Analytical Hierarchy Process hierarchy model composed of three levels. The goal of the decision process is on the first level, the set of criteria by which alternatives are assessed are on the second level and alternatives are on the third level (Saaty, 2012). Moreover, AHP could incorporate group decision making (Omkarprasad \& Kumar, 2006). Since its development, AHP has been applied to almost all fields of decision making.

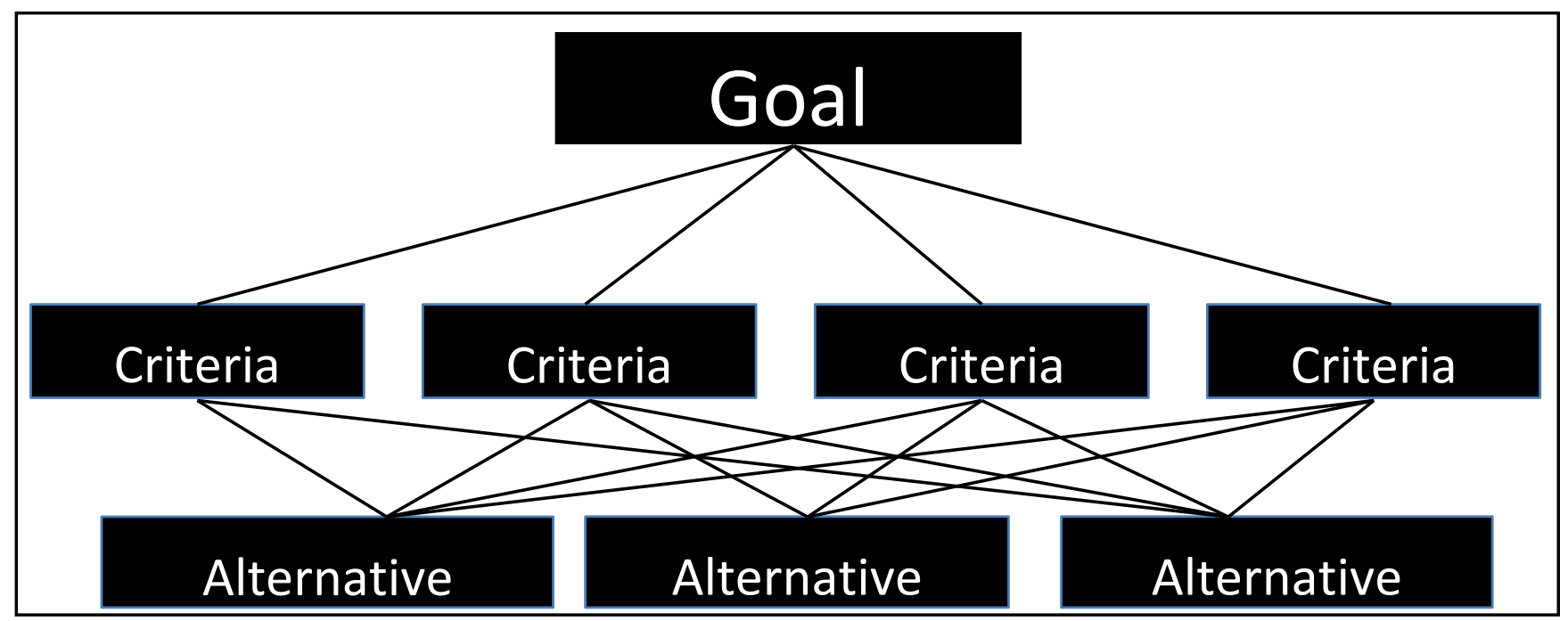

Figure 2: Simple three level decision hierarchy (Saaty, 2012)

Ishizaka and Labib (2009) identified seven steps for a decision making process using AHP:

- Problem modelling: identify goals, criteria and alternatives. 
- Pairwise comparisons conducted on each part of the hierarchy.

- Judgments scale, AHP can evaluate quantitative and qualitative criteria and alternatives using the same preference scale of nine levels.

- Priorities derivation, traditional AHP used an eigenvalue method.

- Consistency check.

- Aggregation of local priorities with respect to all criteria to calculate the global priorities of each alternative using Equation (1).

$P_{i}=\Sigma_{j} w_{j} . l_{i j}$

Where: $P_{i}$ : global priority of the alternative $i$

$w_{j}$ : weight of the criterion $j$

$l_{i j}$ : local priority

- Sensitivity analysis.

According to Al-Shabeeb (2015), AHP often generates good results, provides an approach to define and evaluate alternatives, and presents a powerful hierarchy model to visualize the problem. But considering a large number of alternatives and criteria makes the application of AHP time and effort consuming due to the large number of pairwise comparisons that need to be conducted.

\section{b. The Preference Ranking Organization METHod for Enrichment of Evaluations II (PROMETHEE II)}

PROMETHEE methods were developed by Jean-Pierre Brans and presented for the first time in 1982 at a conference at the Université Laval in Canada. PROMETHEE methods have been extensively studied since then.

PROMETHEE methods are outranking MCDM methods with PROMETHEE I partial ranking and PROMETHEE II total ranking of alternatives. PROMETHEE methods generally consist of a preference function representing each criterion and weights describing their relative importance. The main idea of the PROMETHEE methods is to conduct pairwise comparisons among alternatives regarding each criterion then comprehensively compare them with respect to all criteria (Xiaohann $e t$ al, 2013).

According to Brans (1982), PROMETHEE methods apply the following steps:

- Identify the problem.

- Identify a set of criteria.

- Identify information between criteria (criteria weights).

- Identify Information within criteria (pairwise comparisons and preference functions).

- Identify a set of alternatives.

- Evaluate overall score of each alternative.

Brans (1982) identified six types of preference functions shown in Figure 3 and stressed that efficient alternatives were the alternatives that were non-dominated by other alternatives.

Each preference function identified by Brans (1982) required a number of parameters $(q, p$, or $s)$ to be identified where:

- $q$ : is an Indifference threshold.

- $p:$ is a Strict preference threshold.

- $\quad s$ : is an Intermediate value between $q$ and $p$. 


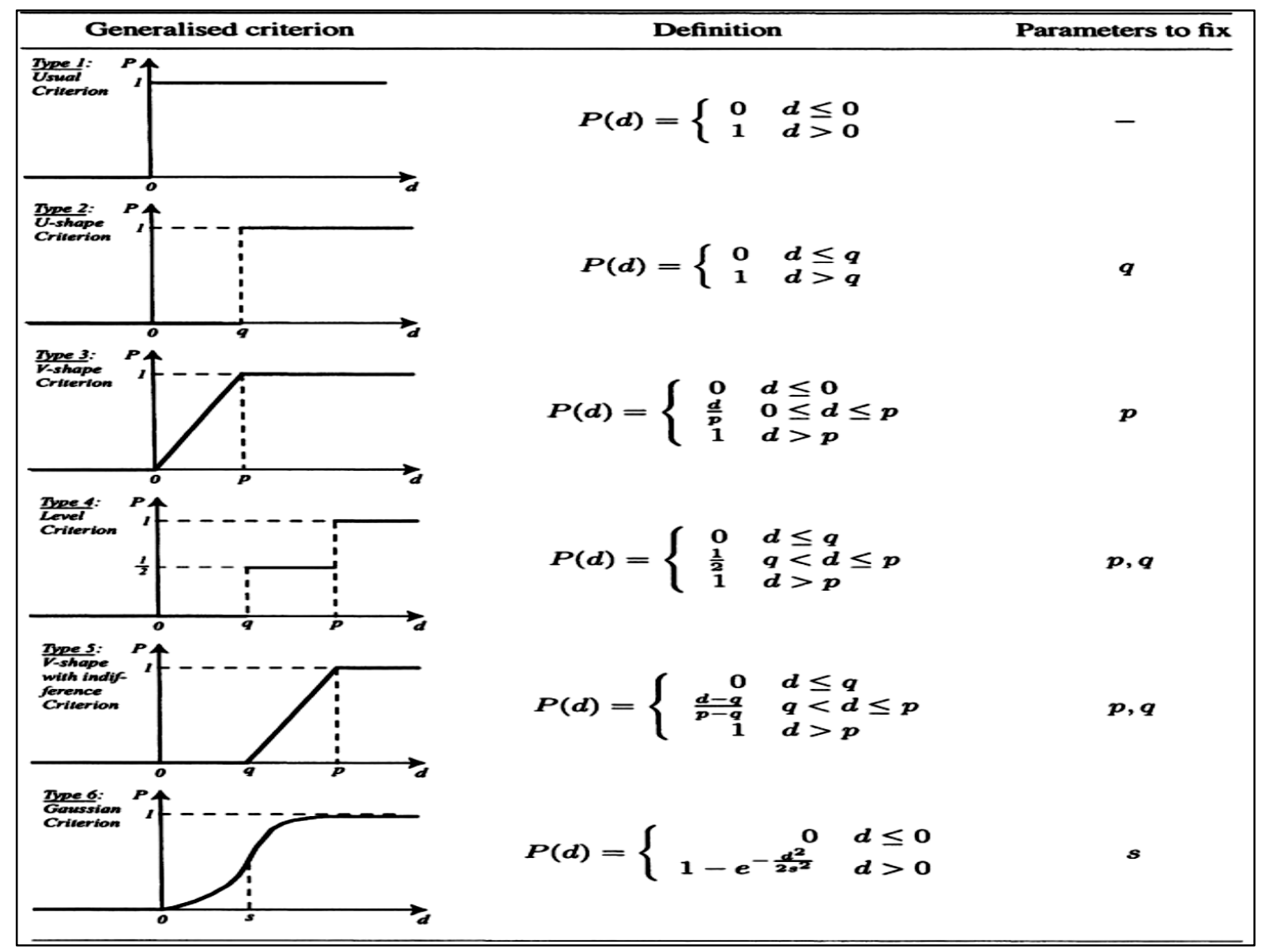

Figure 3: Six types of preference functions (Brans, 1982)

Moreover, Brans (1982) calculated the Preference Indices using Equations (2) and (3):

Let $a, b \in A$ :

$$
\begin{aligned}
& \pi(a, b)=\Sigma_{j} P_{j}(a, b) \cdot w_{j} \\
& \pi(b, a)=\Sigma_{j} P_{j}(b, a) . w_{j}
\end{aligned}
$$

Where, $\pi(a, b)$ expressed the degree by which alternative a was preferred to alternative $b$, and $\pi(b, a)$ express the degree by which alternative $b$ was preferred to alternative $a$.

And

$$
\begin{aligned}
& \pi(a, a)=0 \\
& 0 \leq \pi(a, b) \leq 1 \\
& 0 \leq \pi(b, a) \leq 1 \\
& 0 \leq \pi(a, b)+\pi(b, a) \leq 1 \\
& \pi(a, b) \approx 0 \text { weak global preference of } a \text { over } b . \\
& \pi(a, b) \approx 1 \text { strong global preference of } a \text { over } b .
\end{aligned}
$$

And calculated the Positive, Negative and Net outranking flows using Equations (4), (5) and (6):

Positive outranking flow:

$$
\Phi^{+}(a)=1 /(n-1) \Sigma_{(x \in A)}[\pi(a, x)]
$$

Negative outranking flow:

$$
\Phi^{-}(a)=1 /(n-1) \sum_{(x \in A)}[\pi(x, a]
$$

Net outranking flow:

$$
\Phi(a)=\left[\Phi^{+}(a)+\Phi^{-}(a)\right]
$$


This paper used the type 1 preference function "Usual Criterion" shown in figure 2, no indifference, preference or veto thresholds were considered and the alternative that had higher performance measure on a criterion will be preferred to other alternatives with respect to that criterion.

PROMETHEE methods provide a comprehensive and rational framework for structuring a decision problem, identifying and quantifying its conflicts and synergies, highlighting the main alternative and the structured reasoning behind the identification and quantification.

\section{Employee Evaluation using MCDM methods}

This section describes the application of AHP and PROMETHEE II methods to the officers' evaluation problem. Sensitivity analysis was conducted, and the most stable outcome was adopted. Employee evaluation could be considered as an activity, or a process concerned with the relationship between the employees and their supervisors. (Lidinska \& Jablonsky, 2018). This example considered how members of the U.S. Coast Guard were rated by their superiors. A set of six evaluation criteria were identified, and a set of six anonymous alternatives (officers) were assessed by the identified set of criteria. Results were submitted as part of the officers' service record and results of this assessment were used for the eligibility of officers to be selected for the next superior rank. The evaluation of the employees is conducted regularly, the weights of the evaluation criteria are derived from to the decision maker's perception of their importance. The set of criteria taken into account in the proposed performance evaluation system corresponds to those currently implemented:

- $\quad C_{1}$ : Performance of Duties

- $C_{2}$ : Interpersonal Relations

- $\quad C_{3}$ : Leadership Skills

- $C_{4}$ : Communication Skills

- $\quad C_{5}$ : Personal Qualities

- $C_{6}$ : Representing the Coast Guard

Criteria weights and officers' performance scores for all the officers with respect to all the evaluation criteria are shown as a decision matrix in Table 1.

Table 1: Decision matrix for U.S. Coast Guard Officer Evaluation

\begin{tabular}{|l|c|c|c|c|c|c|}
\hline \multicolumn{1}{|c|}{ Alternative } & $\begin{array}{c}A_{1} \\
\text { Officer } \\
A\end{array}$ & $\begin{array}{c}A_{2} \\
\text { Officer } \\
B\end{array}$ & $\begin{array}{c}A_{3} \\
\text { Officer } \\
C\end{array}$ & $\begin{array}{c}A_{4} \\
\text { Officer } \\
D\end{array}$ & $\begin{array}{c}A_{5} \\
\text { Officer } \\
E\end{array}$ & $\begin{array}{c}A_{6} \\
\text { Officer } \\
F\end{array}$ \\
\hline $\begin{array}{l}C_{l} \text { : Performance of } \\
\text { Duties = 0.296 }\end{array}$ & 0.152 & 0.181 & 0.172 & 0.170 & 0.172 & 0.153 \\
\hline $\begin{array}{l}C_{2} \text { : Interpersonal } \\
\text { Relations =0.254 }\end{array}$ & 0.172 & 0.150 & 0.176 & 0.161 & 0.150 & 0.191 \\
\hline $\begin{array}{l}C_{3}: \text { Leadership } \\
\text { Skills =0.159 }\end{array}$ & 0.193 & 0.156 & 0.186 & 0.166 & 0.162 & 0.137 \\
\hline $\begin{array}{l}C_{4}: \text { Communication } \\
\text { Skills = 0.125 }\end{array}$ & 0.183 & 0.173 & 0.150 & 0.174 & 0.150 & 0.170 \\
\hline $\begin{array}{l}C_{5}: \text { Personal } \\
\text { Qualities = 0.084 }\end{array}$ & 0.196 & 0.170 & 0.161 & 0.162 & 0.157 & 0.155 \\
\hline $\begin{array}{l}C_{6}: \text { Representing } \\
\text { the Coast Guard } \\
0.082\end{array}$ & 0.170 & 0.203 & 0.142 & 0.175 & 0.164 & 0.145 \\
\hline
\end{tabular}

AHP provided the following ranking of alternatives: $A_{1}>\left(A_{2}=A_{3}\right)>A_{4}>A_{6}>A_{5}$, with a global score of of employees: $A_{1}=0.172, A_{2}=0.169, A_{3}=0.169, A_{4}=0.167, A_{5}=0.160$ and $A_{6}=0.162$.

PROMETHEE II provided a different ranking of alternatives: $A_{3}>A_{2}>A_{1}>A_{4}>A_{6}>A_{5}$, with a net outranking flow of alternatives: $\Phi\left(A_{1}\right)=0.139, \Phi\left(A_{2}\right)=0.155, \Phi\left(A_{3}\right)=0.167, \Phi\left(A_{4}\right)=0.063, \Phi\left(A_{5}\right)=$ - 
0.283 and $\Phi(A 6)=-0.241$, where $\Phi$ is a net outranking flow $\Phi(a)=\Phi+(a)-\Phi-(a)$. The higher the net outranking flow the more eligible the officer to promotion.

AHP and PROMETHEE II methods delivered different ranking of officers, sensitivity analysis was conducted on both methods' outcomes to recommend an outcome that best suited this problem and provided the most robust decision. Minimum percentage change required to alter the ranking of officer for the most critical evaluation criterion weight and most critical performance score were calculated. Results are shown in Tables 2, 3, 4 and 5. N/F shown in Tables 4 and 5 stands for a non-feasible value where $\pm 100 \%$ change in the value of that performance score did not affect the original ranking of the officers.

The most critical criterion in this example using AHP was the second criterion $\left(C_{2}\right)$ that represented "Interpersonal Relations" signified by the smallest value (bold number) in table 2. This value represented the minimum percentage change required in the weight of the "Interpersonal Relations" criterion to change the ranking of officers $B$ and $C$, a $6.299 \%$ decrease in its weight change the preference from officer $C$ to officer $B\left(A_{2}>A_{3}\right)$.

Table 2: Minimum percentage change in evaluation criteria weights for U.S. Coast Guard using AHP

\begin{tabular}{|l|c|l|}
\hline \multicolumn{1}{|c|}{ Criteria } & $\begin{array}{c}\text { Percentage } \\
\text { change }\end{array}$ & \multicolumn{1}{|c|}{ New Ranking } \\
\hline$C_{1}:$ Performance of Duties & 8.446 & $A_{1}>A_{2}>A_{3}>A_{4}>\left(A_{5}=A_{6}\right)$ \\
\hline$C_{2}$ : Interpersonal Relations & $\mathbf{- 6 . 2 9 9}$ & $A_{1}>A_{2}>A_{3}>A_{4}>\left(A_{5}=A_{6}\right)$ \\
\hline$C_{3}:$ Leadership Skills & 10.063 & $A_{1}>A_{3}>A_{2}>A_{4}>A_{6}>A_{5}$ \\
\hline$C_{4}:$ Communication Skills & -12 & $A_{1}>A_{3}>A_{2}>A_{4}>A_{6}>A_{5}$ \\
\hline$C_{5}:$ Personal Qualities & -42.857 & $A_{1}>A_{3}>A_{2}>A_{4}>A_{6}>A_{5}$ \\
\hline$C_{6}:$ Representing the Coast Guard & -13.415 & $A_{1}>A_{3}>A_{2}>A_{4}>A_{6}>A_{5}$ \\
\hline
\end{tabular}

The most critical criterion in this example using PROMETHEE II was the first criterion $\left(C_{l}\right)$ that represented "Performance of Duties", signified by the smallest value (bold number) in Table 3. This value represented the minimum percentage change required in the weight of the "Performance of Duties" criterion to change the ranking of officers $A$ and $B$. Where a $2.027 \%$ decrease in its weight changed the preference from officer $B$ to officer $A\left(A_{1}>A_{2}\right)$.

Table 3: Minimum percentage change in evaluation criteria weights for U.S. Coast Guard using PROMETHEE II

\begin{tabular}{|l|c|l|}
\hline \multicolumn{1}{|c|}{ Criteria } & $\begin{array}{c}\text { Percentage } \\
\text { change }\end{array}$ & \multicolumn{1}{c|}{ New ranking } \\
\hline$C_{1}$ : Performance of Duties & $\mathbf{- 2 . 0 2 7}$ & $A_{3}>A_{1}>A_{2}>A_{4}>A_{6}>A_{5}$ \\
\hline$C_{2}$ : Interpersonal Relations & -5.0512 & $A_{2}>A_{3}>A_{1}>A_{4}>A_{6}>A_{5}$ \\
\hline$C_{3}$ : Leadership Skills & -5.660 & $A_{2}>A_{3}>A_{1}>A_{4}>A_{6}>A_{5}$ \\
\hline$C_{4}:$ Communication Skills & 12 & $A_{2}>A_{1}>A_{3}>A_{4}>A_{6}>A_{5}$ \\
\hline$C_{5}$ : Personal Qualities & 19.048 & $A_{2}>A_{1}>A_{3}>A_{4}>A_{6}>A_{5}$ \\
\hline$C_{6}:$ Representing the Coast Guard & 9.756 & $A_{2}>A_{1}>A_{3}>A_{4}>A_{6}>A_{5}$ \\
\hline
\end{tabular}

The most critical performance scores in this example using AHP were $\left(A_{2} C_{1} \& A_{3} C_{2}\right)$, signified by the smallest values (bold numbers) in Table 4 . These values represented the minimum percentage change required in the value of performance score of officer $B$ with respect to "Performance of Duties" criterion $\left(A_{2} C_{1}\right)$ or in the value of performance score of officer $C$ with respect to "Interpersonal Relations" criterion $\left(A_{3} C_{2}\right)$ to change the ranking of officers $B$ and $C\left(A_{2} \& A_{3}\right)$. A $1 \%$ increase in the value of performance score $\left(A_{2} C_{1}\right)$ changed the ranking and preferred officer $B$ over officer $C\left(A_{2}>\right.$ $\left.A_{3}\right)$. A $1 \%$ increase in the value of performance score $\left(A_{3} C_{2}\right)$ changed the ranking and preferred officer $C$ to officer $B\left(A_{3}>A_{2}\right)$.

Table 4: Minimum percentage change in performance scores for U.S. Coast Guard Officers using AHP 


\begin{tabular}{|c|c|c|}
\hline $\begin{array}{c}\text { Performance } \\
\text { Measure }\end{array}$ & $\begin{array}{c}\text { Percentage } \\
\text { change }\end{array}$ & New ranking \\
\hline$A_{l} C_{l}$ & -4 & $\left(A_{1}=A_{3}\right)>A_{2}>A_{4}>A_{6}>A_{5}$ \\
\hline$A_{2} C_{1}$ & 1 & $A_{1}>A_{2}>A_{3}>A_{4}>A_{6}>A_{5}$ \\
\hline$A_{3} C_{1}$ & 2 & $A_{1}>A_{3}>A_{2}>A_{4}>A_{6}>A_{5}$ \\
\hline$A_{3} C_{1}$ & -2 & $A_{1}>A_{2}>\left(A_{3}=A_{4}\right)>A_{6}>A_{5}$ \\
\hline$A_{4} C_{1}$ & 3 & $A_{1}>\left(A_{2}=A_{3}=A_{4}\right)>A_{6}>A_{5}$ \\
\hline$A_{5} C_{1}$ & 3 & $A_{1}>\left(A_{2}=A_{3}\right)>A_{4}>A_{5}>A_{6}$ \\
\hline$A_{6} C_{1}$ & -3 & $A_{1}>\left(A_{2}=A_{3}\right)>A_{4}>A_{5}>A_{6}$ \\
\hline$A_{1} C_{2}$ & -4 & $A_{1}>A_{2}>A_{3}>A_{4}>A_{6}>A_{5}$ \\
\hline$A_{2} C_{2}$ & 2 & $A_{1}>A_{2}>A_{3}>A_{4}>A_{6}>A_{5}$ \\
\hline$A_{2} C_{2}$ & -2 & $A_{1}>A_{3}>\left(A_{2}=A_{4}\right)>A_{6}>A_{5}$ \\
\hline$A_{3} C_{2}$ & 1 & $A_{1}>A_{3}>A_{2}>A_{4}>A_{6}>A_{5}$ \\
\hline$A_{4} C_{2}$ & 3 & $A_{1}>\left(A_{2}=A_{3}=A_{4}\right)>A_{6}>A_{5}$ \\
\hline$A_{5} C_{2}$ & 4 & $A_{1}>\left(A_{2}=A_{3}\right)>A_{4}>A_{5}>A_{6}$ \\
\hline$A_{6} C_{2}$ & -3 & $A_{1}>\left(A_{2}=A_{3}\right)>A_{4}>A_{5}>A_{6}$ \\
\hline$A_{1} C_{3}$ & -5 & $A_{1}>A_{3}>A_{2}>A_{4}>A_{6}>A_{5}$ \\
\hline$A_{2} C_{3}$ & 2 & $A_{1}>A_{2}>A_{3}>A_{4}>A_{6}>A_{5}$ \\
\hline$A_{3} C_{3}$ & 2 & $A_{1}>A_{3}>A_{2}>A_{4}>A_{6}>A_{5}$ \\
\hline$A_{4} C_{3}$ & 5 & $A_{1}>\left(A_{2}=A_{3}=A_{4}\right)>A_{6}>A_{5}$ \\
\hline$A_{5} C_{3}$ & 5 & $A_{1}>\left(A_{2}=A_{3}\right)>A_{4}>\left(A_{5}=A_{6}\right)$ \\
\hline$A_{6} C_{3}$ & -6 & $A_{1}>\left(A_{2}=A_{3}\right)>A_{4}>\left(A_{5}=A_{6}\right)$ \\
\hline$A_{l} C_{4}$ & -8 & $\left(A_{1}=A_{2}\right)>A_{3}>A_{4}>A_{6}>A_{5}$ \\
\hline$A_{2} C_{4}$ & 2 & $A_{1}>A_{2}>A_{3}>A_{4}>A_{6}>A_{5}$ \\
\hline$A_{3} C_{4}$ & 2 & $A_{1}>A_{3}>A_{2}>A_{4}>A_{6}>A_{5}$ \\
\hline$A_{4} C_{4}$ & 6 & $A_{1}>\left(A_{2}=A_{3}=A_{4}\right)>A_{6}>A_{5}$ \\
\hline$A_{5} C_{4}$ & 7 & $A_{1}>\left(A_{2}=A_{3}\right)>A_{4}>\left(A_{5}=A_{6}\right)$ \\
\hline$A_{6} C_{4}$ & -6 & $A_{1}>\left(A_{2}=A_{3}\right)>A_{4}>A_{5}>A_{6}$ \\
\hline$A_{1} C_{5}$ & -11 & $A_{1}>A_{2}>A_{3}>A_{4}>A_{6}>A_{5}$ \\
\hline$A_{2} C_{5}$ & 3 & $A_{1}>A_{2}>A_{3}>A_{4}>A_{6}>A_{5}$ \\
\hline$A_{3} C_{5}$ & 3 & $A_{1}>A_{3}>A_{2}>A_{4}>A_{6}>A_{5}$ \\
\hline$A_{4} C_{5}$ & 9 & $A_{1}>\left(A_{2}=A_{3}=A_{4}\right)>A_{6}>A_{5}$ \\
\hline$A_{5} C_{5}$ & 10 & $A_{1}>\left(A_{2}=A_{3}\right)>A_{4}>\left(A_{5}=A_{6}\right)$ \\
\hline$A_{6} C_{5}$ & -10 & $A_{1}>\left(A_{2}=A_{3}\right)>A_{4}>\left(A_{5}=A_{6}\right)$ \\
\hline$A_{l} C_{6}$ & -13 & $A_{1}>A_{3}>A_{2}>A_{4}>A_{6}>A_{5}$ \\
\hline$A_{2} C_{6}$ & 4 & $A_{1}>A_{2}>A_{3}>A_{4}>A_{6}>A_{5}$ \\
\hline$A_{3} C_{6}$ & 4 & $A_{1}>A_{3}>A_{2}>A_{4}>A_{6}>A_{5}$ \\
\hline$A_{4} C_{6}$ & 9 & $A_{1}>\left(A_{2}=A_{3}=A_{4}\right)>A_{6}>A_{5}$ \\
\hline$\overline{A_{5} C_{6}}$ & 10 & $A_{1}>\left(A_{2}=A_{3}\right)>A_{4}>\left(A_{5}=A_{6}\right)$ \\
\hline$A_{6} C_{6}$ & -11 & $A_{1}>\left(A_{2}=A_{3}\right)>A_{4}>\left(A_{5}=A_{6}\right)$ \\
\hline
\end{tabular}

The most critical performance scores in this example using PROMETHEE II were $\left(A_{1} C_{1}, A_{3} C_{1}, A_{4} C_{1}\right.$, $A_{5} C_{1}, A_{6} C_{1}, A_{2} C_{2}, A_{5} C_{2}, A_{2} C_{4}, A_{3} C_{4}, A_{4} C_{4} \& A_{5} C_{4}$ ), signified by the smallest values (bold numbers) in Table 5. These values represented the minimum percentage change required in value of performance score of officers $A, C, D, E$ or $F$ with respect to "Performance of Duties" criterion $\left(A_{l} C_{1}, A_{3} C_{1}, A_{4} C_{l}\right.$, $A_{5} C_{1}, A_{5} C_{1}$ or $A_{6} C_{1}$ ), in the value of performance score of officers $B$ or $E$ with respect to "Interpersonal Relations" criterion $\left(A_{2} C_{2}\right.$ or $\left.A_{5} C_{2}\right)$, in the value of performance score of officers $B, C, D$ or $E$ with respect to "Communication Skills" criterion $\left(A_{2} C_{4}, A_{3} C_{4}, A_{4} C_{4}\right.$ or $\left.A_{5} C_{4}\right)$ to change the ranking of the officers. A $1 \%$ increase in the value of $\left(A_{l} C_{1}\right)$ changed the ranking of officers $A$ and $C\left(A_{1}>A_{3}\right)$. A $1 \%$ decrease in the value of $\left(A_{3} C_{1}\right)$ changed the ranking of officers $C$ and $D\left(A_{4}>A_{3}\right)$. A $1 \%$ decrease in the value of $\left(A_{5} C_{1}\right)$ changed the ranking of officers $B$ and $D\left(A_{4}>A_{2}\right)$. A $1 \%$ decrease in the value of $\left(A_{6} C_{1}\right)$ changed the ranking of officers $A$ and $C\left(A_{1}>A_{3}\right)$ and officers $E$ and $F\left(A_{5}>A_{6}\right)$. A $1 \%$ 
increase in the value of $\left(A_{2} C_{2}\right)$ changed the ranking of officers $B$ and $C\left(A_{2}>A_{3}\right)$. A $1 \%$ decrease in the value of $\left(A_{2} C_{2}\right)$ changed the ranking of officers $A$ and $B\left(A_{1}>A_{2}\right)$ and officers $E$ and $F\left(A_{5}>A_{6}\right)$. A $1 \%$ increase in the value of $\left(A_{4} C_{1}\right)$ changed the ranking of officers $D$ and $C\left(A_{4}>A_{3}\right)$. A $1 \%$ increase in the value of $\left(A_{5} C_{1}\right)$ changed the ranking of officers $C$ and $A\left(A_{1}>A_{3}\right)$ and officers $E$ and $F\left(A_{5}>\right.$ $\left.A_{6}\right)$. A $1 \%$ decrease in the value of $\left(A_{5} C_{1}\right)$ changed the ranking of officers $B$ and $D\left(A_{4}>A_{2}\right)$. A $1 \%$ change in the value of $\left(A_{5} C_{2}\right)$ changed the ranking of officers $B$ and $C\left(A_{2}>A_{3}\right)$. A $1 \%$ increase in the values of $\left(A_{2} C_{4}\right.$ or $\left.A_{5} C_{4}\right)$ changed the ranking of officers $B$ and $C\left(A_{2}>A_{3}\right)$. A $1 \%$ decrease in the values of $\left(A_{3} C_{4}, A_{4} C_{4}\right)$ changed the ranking of officers $B$ and $C\left(A_{2}>A_{3}\right)$.

Table 5: Minimum percentage change in performance scores for U.S. Coast Guard Officers using PROMETHEE II

\begin{tabular}{|c|c|c|}
\hline $\begin{array}{c}\text { Performance } \\
\text { Measure }\end{array}$ & $\begin{array}{l}\text { Percentage } \\
\text { change }\end{array}$ & New ranking \\
\hline$A_{l} C_{1}$ & 1 & $A_{1}>A_{3}>A_{2}>A_{4}>A_{6}>A_{5}$ \\
\hline$A_{2} C_{1}$ & -5 & $A_{3}>A_{1}>A_{4}>A_{2}>A_{5}>A_{6}$ \\
\hline$A_{3} C_{1}$ & -1 & $A_{4}>A_{2}>A_{1}>A_{3}>A_{5}>A_{6}$ \\
\hline$A_{4} C_{1}$ & 1 & $A_{4}>A_{2}>A_{1}>A_{3}>A_{6}>A_{5}$ \\
\hline$A_{5} C_{l}$ & -1 & $A_{3}>A_{4}>A_{2}>A_{1}>A_{6}>A_{5}$ \\
\hline$\overline{A_{5} C_{1}}$ & 1 & $A_{2}>A_{1}>A_{3}>A_{4}>A_{5}>A_{6}$ \\
\hline$A_{6} C_{1}$ & -1 & $A_{1}>A_{3}>A_{2}>A_{4}>A_{5}>A_{6}$ \\
\hline$A_{l} C_{2}$ & 2 & $A_{1}>A_{2}>A_{3}>A_{4}>A_{6}>A_{5}$ \\
\hline$A_{2} C_{2}$ & 1 & $A_{2}>A_{3}>A_{3}>A_{4}>A_{6}>A_{5}$ \\
\hline$A_{2} C_{2}$ & -1 & $A_{3}>A_{1}>A_{2}>A_{4}>A_{5}>A_{6}$ \\
\hline$A_{3} C_{2}$ & -2 & $A_{1}>A_{2}>A_{3}>A_{4}>A_{6}>A_{5}$ \\
\hline$A_{4} C_{2}$ & 6 & $A_{5}>A_{2}>A_{3}>A_{4}>A_{1}>A_{6}$ \\
\hline$A_{4} C_{2}$ & -6 & $A_{2}>A_{3}>A_{1}>A_{4}>A_{5}>A_{6}$ \\
\hline$A_{5} C_{2}$ & 1 & $A_{2}>A_{3}>A_{1}>A_{4}>A_{6}>A_{5}$ \\
\hline$A_{5} C_{2}$ & -1 & $A_{2}>A_{3}>A_{1}>A_{4}>A_{6}>A_{5}$ \\
\hline$A_{6} C_{2}$ & -9 & $A_{3}>A_{1}>A_{2}>A_{4}>A_{5}>A_{6}$ \\
\hline$A_{1} C_{3}$ & -11 & $A_{3}>A_{2}>A_{4}>A_{1}>A_{6}>A_{5}$ \\
\hline$A_{2} C_{3}$ & 4 & $A_{2}>A_{3}>A_{1}>A_{4}>A_{6}>A_{5}$ \\
\hline$A_{3} C_{3}$ & -9 & $A_{2}>A_{1}>A_{4}>A_{3}>A_{6}>A_{5}$ \\
\hline$A_{4} C_{3}$ & -3 & $A_{3}>A_{2}>A_{1}>A_{4}>A_{5}>A_{6}$ \\
\hline$A_{5} C_{3}$ & 3 & $A_{3}>A_{2}>A_{1}>A_{4}>A_{6}>A_{5}$ \\
\hline$A_{6} C_{3}$ & 12 & $A_{3}>A_{1}>A_{2}>A_{4}>A_{6}>A_{5}$ \\
\hline$A_{l} C_{4}$ & -5 & $A_{2}>A_{3}>A_{4}>A_{1}>A_{6}>A_{5}$ \\
\hline$A_{2} C_{4}$ & 1 & $A_{2}>A_{3}>A_{1}>A_{4}>A_{6}>A_{5}$ \\
\hline$A_{3} C_{4}$ & -1 & $A_{2}>A_{3}>A_{1}>A_{4}>A_{6}>A_{5}$ \\
\hline$A_{4} C_{4}$ & -1 & $A_{2}>A_{3}>A_{1}>A_{4}>A_{6}>A_{5}$ \\
\hline$A_{5} C_{4}$ & 1 & $A_{2}>A_{3}>A_{1}>A_{4}>A_{6}>A_{5}$ \\
\hline$A_{6} C_{4}$ & 2 & $A_{3}>A_{1}>A_{2}>A_{4}>A_{6}>A_{5}$ \\
\hline$A_{l} C_{5}$ & -11 & $A_{2}>A_{3}>A_{1}>A_{4}>A_{6}>A_{5}$ \\
\hline$A_{2} C_{5}$ & -4 & $A_{3}>A_{1}>A_{2}>A_{4}>A_{6}>A_{5}$ \\
\hline$A_{3} C_{5}$ & -3 & $A_{2}>A_{1}>A_{3}>A_{4}>A_{6}>A_{5}$ \\
\hline$A_{4} C_{5}$ & 5 & $A_{3}>A_{1}>A_{2}>A_{4}>A_{6}>A_{5}$ \\
\hline$A_{5} C_{5}$ & 3 & $A_{2}>A_{1}>A_{3}>A_{4}>A_{5}>A_{6}$ \\
\hline$A_{6} C_{5}$ & 4 & $A_{2}>A_{1}>A_{3}>A_{4}>A_{6}>A_{5}$ \\
\hline$A_{1} C_{6}$ & 3 & $A_{1}>A_{3}>A_{2}>A_{4}>A_{6}>A_{5}$ \\
\hline$A_{2} C_{6}$ & -12 & $A_{3}>A_{1}>A_{2}>A_{4}>A_{6}>A_{5}$ \\
\hline$A_{3} C_{6}$ & $\mathrm{~N} / \mathrm{F}$ & -- \\
\hline$A_{4} C_{6}$ & -3 & $A_{1}>A_{3}>A_{2}>A_{4}>A_{6}>A_{5}$ \\
\hline$A_{5} C_{6}$ & 6 & $A_{3}>A_{2}>A_{1}>A_{4}>A_{5}>A_{6}$ \\
\hline$A_{6} C_{6}$ & $\mathrm{~N} / \mathrm{F}$ & -- \\
\hline
\end{tabular}


This problem provided examples of uncertainties in evaluation criteria weights and employees performance scores. Actions were considered to address them:

SITUATION ONE: AHP and PROMETHEE II delivered different outcomes. AHP required a 6.299\% decrease in the value of most critical criterion weight (i.e. "Interpersonal Relations") to alter the ranking of officers, while PROMETHEE II required a 2.027\% decrease to the value of the most critical criterion weight (i.e. "Performance of Duties") to alter the ranking of officers. AHP was 3.108 times less sensitive to changes in the value of the most critical criterion weight than PROMETHEE II. Decision makers often prefer a method that is resilient to changes in criteria weights, they often apply MCDM methods to aid them in delivering appropriate and fair decisions (Razmak \& Aouni, 2015). A robust method provides more stable outcomes with less sensitivity to risk and uncertainties. AHP would be recommended for this problem when decision makers were uncertain of criteria weights.

SITUATION TWO: AHP required a $1 \%$ increase to the values of most critical performance scores to alter the ranking of the officers. PROMETHEE II also required a $1 \%$ change to the values of the most critical performance scores to alter the ranking of the officers. Both methods had the same sensitivity towards uncertainty in performance scores; AHP had two critical performance scores while PROMETHEE II had fourteen critical performance scores. Decision makers often prefer a method that is less sensitive to changes in the values of the performance scores, they often apply MCDM methods to aid them in delivering appropriate and fair decisions (Razmak \& Aouni, 2015). A robust method provides more stable outcomes with less sensitivity to risk and uncertainties. AHP would also be recommended for this problem if decision makers were uncertain of performance scores. Analysis of these results showed that the number of critical performance scores and the number of critical criteria should be taken into consideration when recommending a MCDM method. From Tables 2 and 4, AHP had one critical criterion and two critical performance scores, from Tables 3 and 5 PROMETHEE II had one critical criterion and fourteen critical performance scores. AHP would be recommended for this problem when the number of critical performance scores and the number of critical criteria were taken into consideration.

SITUATION THREE: AHP was less sensitive than PROMETHEE II to changes in the values of the most critical criteria weights and had fewer critical performance scores. The number of most critical criteria and most critical performance scores a method has for a certain problem provides guidance towards the number of risk factors the method is vulnerable to. The higher the number of most critical criteria and most critical performance scores, the higher the number of risk factors a method is sensitive towards that might change the final outcome of the method. Moreover, the lower the minimum percentage change required in the most critical criteria and the most critical performance measure, the higher the sensitivity of the final outcome of a method to changes in the inputs (i.e. risk and uncertainty). Recommending AHP for this problem when risk and uncertainty would affect both criteria weights and / or performance scores may provide a more robust outcome for this example.

In all three situations, AHP would be recommended for this problem. 


\section{Discussion}

The two methods provided different outcomes when applied to the same problem. This was because methods deal differently with performance scores, and criteria weights often have different impact from one method to another, moreover in MCDM problems a "correct" result does not exist (Tscheikner-Gratl et al, 2017). If two methods delivered significantly different results then, at least one method was invalid (Haddad et al, 2018). MCDM methods deliver a best compromise solution.

The minimum percentage change for all evaluation criteria and employee performances with respect to all criteria required to change the outcome of a method was calculated. Critical criteria and critical performance scores were identified. Critical criteria and critical performance scores are the criteria and the performance scores that required the least amount of change in their value to change the outcome of a method. Conducting sensitivity analysis on both criteria weights and performance scores of a problem and analysing the robustness of the outcome of the method to changes in both criteria weights and performance scores was used as an indicator for the robustness of the outcome of a MCDM method when uncertainty affected both inputs of the problem.

The importance of identifying the most critical criteria and the most critical performance scores might help decision makers in achieving a robust outcome and will make decision makers give extra attention to these factors when providing judgments (i.e. setting evaluation criteria weights and employee performance scores with respect to criteria).

This paper considered the evaluation of coastguard officers. The following method was used:

1. Qualitative and quantitative risk analysis should be conducted first.

2. Apply MCDM methods to the evaluation of performance of coast guard officers.

3. Conduct sensitivity analysis on the outcome of the methods.

4. Results from sensitivity analysis and risk analysis should be used to recommend a method that is least sensitive to factors highlighted by the qualitative and quantitative risk analysis.

5. A MCDM method might be recommended for a problem even though it was highly sensitive to changes in a certain factor, but that factor might not be highlighted during the risk analysis.

Also a MCDM method might be excluded from the subset of candidate methods if it was sensitive to factors highlighted by the risk analysis.

6. The most stable outcome was adopted. In this case that was AHP.

Then:

SUGGESTION ONE - Uncertainty in Criteria Weights: If managers or HR staff are uncertain of evaluation criteria weights and / or anticipate a risk factor of high severity that could affect evaluation criteria weights, then a method that is less sensitive to changes in evaluation criteria weights should be recommended for the problem. If methods had the same sensitivity to uncertainty in evaluation criteria weights, then the method that had fewer critical evaluation criteria should be recommended for the problem.

SUGGESTION TWO - Uncertainty in Performance Scores: If managers or HR staff are uncertain of performance scores of employees with respect to evaluation criteria and / or anticipate a risk factor of high severity that could affect the performance scores, then a method that is less sensitive to changes in the performance scores should be recommended for the problem. If methods had the same 
sensitivity to uncertainty in the performance scores, then the method that had fewer critical performance scores should be recommended for the problem.

SUGGESTION THREE - Uncertainty in Inputs: If managers or HR staff are uncertain and / or anticipate a risk factor of high severity that could affect both evaluation criteria weights and performance scores of employees with respect to evaluation criteria, then a method that is least sensitive to changes in these factors should be recommended for the problem. If methods had the same sensitivity to uncertainty in these factors then the method that had fewer critical evaluation criteria weights and /or performance scores should be recommended for the problem and a best compromise between these factors would be recommended.

\section{Conclusions and Future Work}

The large number and the variety of existing MCDM methods can confuse managers or HR staff, resulting in inappropriate pairing of methods and problems. The authors are not suggesting that one MCDM method is better than another, but that one MCDM method could deliver a more robust outcome than another for a specific HR problem. To recommend a single method for a specific problem, risk and uncertainty factors needed to be considered.

This paper applied two MCDM methods based on two different approaches to employee evaluation problem. Both performance scores and criteria weights were studied, and sensitivity analysis applied to performance scores and criteria weights to give a recommendation. The proposed model provided objectiveness and transparency for the HRM decision. The model was tested on real data sets, sensitivity analysis was conducted, and the most stable outcome was adopted.

The authors are now comparing the stability of the outcomes of other MCDM methods. Perfect consistency in real life problems is often hard to achieve. To investigate this, the authors intend to apply a number of MCDM methods to various uncertain, fuzzy and risky problems.

The authors will apply PROMETHEE II with indifference, preference and veto thresholds to other problems and analyse the stability of the outcome of the method in certain and uncertain environments.

Future work will consider more problems with larger number of employees and evaluation criteria. AHP, PROMETHEE II, WASPAS, and TOPSIS will be applied to these problems and the stability of the outcome of these methods will be analyzed in certain and uncertain environments. In addition, decision making systems will be applied to energy (Sanders 2017a; Sanders et al 2019a), assistive technology (Sanders 2017b, 2018; Sanders et al 2019b, c, d), and robotics (Sanders et al 2018a, b, c). 


\section{References:}

Al-Shabeeb, A. R. (2015) “A Modified Analytical Hierarchy Process Method to Select Sites For Groundwater Recharge in Jordan", PhD Dissertation, University of Leicester, U.K.

Antoniou, F. and Aretoulis, G.N. (2018) 'Comparative analysis of multi-criteria decision making methods in choosing contract type for highway construction in Greece', Int. J. Management and Decision Making, Vol. 17, No. 1, pp.1-28.

Bella, S., Brown, S. and Weiss, J. (2018) “A conceptual framework for leveraging team composition decisions to build human capital”, Human Resource Management Review, Vol. 28, pp. 450-463. doi.org/10.1016/j.hrmr.2017.06.003

Brans, J. P. (1982) "Lingenierie de la decision. Elaboration sinstruments daide a la decision. Methode PROMETHEE”, Nadeau R. Landry, M. (Eds), Laide a la Decisiobn: Nature, Instruments et Prespectives Davenir. Presses de Universite Laval, Quebec, Canada. pp. 183 - 214.

Comes, T., Hiete, M. and Schultmann, F. (2013). "An Approach to Multi-Criteria Decision Problems Under Severe Uncertainty”, J. Multi-Crit. Decis. Anal. Vol. 20, pp.29-48. DOI:10.1002/mcda.1487.

Danesh, D., Ryan, M.J. and Abbasi, A. (2018) 'Multi-criteria decision-making methods for project portfolio management: a literature review', Int. J. Management and Decision Making, Vol. 17, No. 1, pp.75-94.

Durbach, I. and Stewart, T. (2012) "Modeling uncertainty in multi-criteria decision analysis", EJOR, Vol. 223, pp. 1-14.

Eldarandaly, K., Ahmed, A. and AbdelAziz, N. (2009) "An Expert System for Choosing the Suitable MCDM Method for Solving a Spatial Decision Problem”, Proceedings of the 9th Int. Conf. on Production Engineering,

Design and Control, Alexandria, Egypt.

Expert Choice, 2013. Expert Choice Desktop. [online] Available at: http://www.expertchoice.com . [Accessed 3 January 2018].

Eyvindson, K., Öhman, K. and Nordström, E. M. (2018) "Using uncertain preferential information from stakeholders to assess the acceptability of alternative forest management plans”, J. Multi-Crit. Decis. Anal. 2018, Vol. 25, pp. 43-52.

Grechuk, B. and Zabarankin, M. (2018) "Direct data-based decision making under uncertainty. EJOR, Vol. 267, pp.200-211.

Haddad, M. (2017) “A Framework That Uses Sensitivity Analysis to Select Multi Criteria Decision Making Methods", Journal of computing in systems and engineering, Vol. 18, pp. 413-419.

Haddad, M. and Sanders, D. (2018) "Selection of Discrete Multiple Criteria Decision Making Methods in the Presence of Risk and Uncertainty", Operations Research Perspectives, Accepted and In Press. doi.org/10.1016/j.orp.2018.10.003.

Haddad, M., Sanders, D., Bausch, N., Tewkesbury, G., Gegov, A. and Hassan, M. (2018). "Learning to make intelligent decisions using an expert system for the intelligent selection of either PROMITHEE II or the Analytical Hierarchy Process", IEEE Proceedings of the SAI Conference on Intelligent Systems, London, pp. 662 - 668.

Haddad, M., Sanders, D., Bausch, N., Tewkesbury GE., Gegov, A. and Hassan, M. (2019). "Learning to make intelligent decisions using PROMITHEE II and the Analytical Hierarchy Process", Intelligent Systems and Applications. Advances in Intelligent Systems and Computing, Vol. 868, pp: 1303-1316.

Ishizaka, A. and Labib, A. (2009) "Analytic Hierarchy Process and Expert Choice: Benefits and Limitations”, ORInsight, Vol. 22(4), pp. 201-220.

Ishizaka, A. and Siraj, S. (2018) "Are multi-criteria decision-making tools useful? An experimental comparative study of three methods", EJOR, Vol. 264, pp. 462-471.

Kornyshova, E. and Salinesi, C. (2007) "MCDM Techniques Selection Approaches: State of the Art", Proceedings of the 2007 IEEE Symposium on Computational Intelligence in Multicriteria Decision Making (MCDM 2007).

Lidinska, L. and Jablonsky, J. (2018) “AHP model for performance evaluation of employees in a Czech management consulting company”, CEJOR, Vol. 26, pp. 239 - 258. doi.org/10.1007/s10100-017-0486-7.

Maleki, H. and Zahir, S. A. (2013) "Comprehensive Literature Review of the Rank Reversal Phenomenon in the Analytic Hierarchy Process", J. Multi-Crit. Decis. Anal. Vol. 20, pp. 141-155.

Mammadova, M. and Jabrayilova, Z. (2015) "Decision-making support for human resources management on the basis of multi-criteria optimization method", Proc 9th Int' Conf' on Application of Information and Communication Technologies, pp. 579-582. DOI: 10.1109/ICAICT.2015.7338627

Norese, M. F., (2016) “A model-based process to improve robustness in Multicriteria Decision Aiding interventions," J. Multi-Crit. Decis. Anal. Vol. 23, pp. 183-196. DOI 10.1002/mcda.1597

Olson, D., Mechitov, A. and Moshkovich, H. (2007) "Learning aspects of decision aids", Proceedings of the 15th Int. Conf. on MCDM'00, IEEE Symposium on Computational Intelligence in Multicriteria Decision Making (MCDM 2007), Ankara, Turkey.

Omkarprasad S. and Kumar, S. (2006) "Analytical hierarchy process: An overview of applications", EJOR, Vol. 169, pp. 1-29.

Ozernoy, V. (1992) "Choosing the Best Multiple Criteria Decision Making Method", INFOR, Vol. $30(2)$, pp. $159-171$. 
Project Management Institute. (2004). "A guide to the project management body of knowledge (PMBOK)", 6th ed. Newtown Square, Pa, USA.

Razmak, J. and Aouni, B. (2015) "Decision Support System and Multi-Criteria Decision Aid: A State of the Art and Perspectives, J. Multi-Crit. Decis. Anal. Vol. 22, pp. 101-117.

Renkema, M., Meijerink, J. and Bondarouk, T. (2017) "Advancing multilevel thinking in human resource management research: Applications and guidelines”, Human Resource Management Review, Vol. 27, pp. $397-415$. DOI: $10.1016 / \mathrm{j} . \mathrm{hrmr} .2017 .03 .001$.

Roy, B. (1985) "Methodologie multicitere a la Decision: Methodes et Cas", Economica.

Saaty R. W. (1987) “THE ANALYTIC HIERARCHY PROCESS-WHAT IT IS AND HOW IT IS USED”, Mat/d Modelling, Vol. 9(3-5), pp. 161-176.

Saaty T. L. (1994) "How to Make a Decision: The Analytic Hierarchy Process", INTERFACES, Vol. 24 (6), pp. 19- 43.

Saaty, T. (2008) "Decision making with the analytic hierarchy process", Int. J. Services Sciences, Vol. 1 (1). DOI:10.1504/IJSSci.2008.01759.

Saaty, T. (2012) "Models, Methods, Concepts and Applications of the Analytic Hierarchy Process", International Series in Operations Research and Management Science. 2nd ed. 2012 Springer.

Saaty, T. and Ergu, D. (2015) "When is a Decision Making Method Trustworthy? Criteria for Evaluating Multi-Criteria Decision Making Methods", International Journal of Information Technology \& Decision Making, Vol. 14(6), DOI: 10.1141/S021962201550025X.

Saltelli, A., Tarantola, S. and Campolongo, F. (2000) "Sensitivity Analysis as an Ingredient of Modelling”, Statistical Science, Vol. 15(4), pp. 377 - 395.

Sanders, D. (2017a) "New method to design large scale high-recirculation airlift reactors", Proc Institute of Civil Engineering, Jrnl Environmental Engineering and Science, Vol. 12 (3), pp. 62-78.

Sanders, DA. (2017b) "Using self-reliance factors to decide how to share control between human powered wheelchair drivers and ultrasonic sensors", IEEE Transactions on Neural Systems and Rehabilitation Engineering, Vol 25 (8), pp. 1221-1229.

Sanders, D (2018) "Non-model-based control of a wheeled vehicle pulling two trailers to provide early powered mobility and driving experiences", IEEE Transactions on Neural Systems and Rehabilitation Engineering, vol 26, no. 1, pp. 96 - 104.

Sanders, D., Gegov, A,. and Ndzi, D. (2018a) "Knowledge-based expert system using a set of rules to assist a tele-operated mobile robot" Studies in Computational Intelligence, Vol. 751, pp. 371-392.

Sanders, D., Sanders, H., Gegov, A., \& Ndzi, D. (2018b) "Rule-based system to assist a tele-operator with driving a mobile robot", Lecture Notes in Networks and Systems, Vol. 16, pp. 599-615.

Sanders, D., Ndzi, D., Chester, S., and Malik, M. (2018c) “Adjustment of Tele-Operator Learning When Provided with Different Levels of Sensor Support While Driving Mobile Robots”, Lecture Notes in Networks and Systems, Vol. 16, pp. 548-558.

Sanders, D., Robinson, CD., Hassan, M., Haddad, M., Gegov, A and Ahmed, N. (2019a) "Making decisions about saving energy in Compressed Air Systems using Ambient Intelligence and AI". Advances in Intelligent Systems and Computing, Vol. 869, pp: 12291236.

Sanders, D., Gegov, A., Haddad, M., Ikwan, F., Wiltshire, D. and Tan, YC. (2019b) “A Rule-based Expert System to decide on direction and speed of a powered wheelchair", Intelligent Systems and Applications. Intelligent Systems and Applications, Vol. 868, pp: 822838.

Sanders, D., Tewkesbury, GE., Parchizadeh, H., Robertson, J., Omoarebun, PE., and Malik, M. (2019c) "Learning to drive with and without intelligent computer systems and sensors to assist", Intelligent Systems and Applications. Advances in Intelligent Systems and Computing, Springer, Vol. 868, pp 1171-1181.

Sanders, DA., Gegov, A., Tewkesbury, GE., Khusainov, R. (2019d) "Sharing Driving Between a Vehicle Driver and a Sensor System Using Trust-Factors to Set Control Gains", Intelligent Systems and Applications. Advances in Intelligent Systems and Computing, Vol. 868, pp 1182-1195.

Saridakis, G., Lai, Y. and Cooper, C. (2017) "Exploring the relationship between HRM and firm performance: A meta-analysis of longitudinal studies", Human Resource Management Review, Vol. 27, pp. 87-96. doi.org/10.1016/j.hrmr.2016.09.005.

Scholten, L., Schuwirth, N., Reichert, P. and Lienert, J. (2015) "Tackling uncertainty in multi-criteria decision analysis-An application to water supply infrastructure planning”, EJOR, Vol. 242, pp. 243-260.

Sun, X., Gollnick, V. and Stumpf, E. (2011) "Robustness Consideration in Multi-Criteria Decision Making to an Aircraft Selection Problem”, J. Multi-Crit. Decis. Anal. Vol. 18, pp. 55-64.

Tscheikner-Gratl, F., Egger,P., Rauch, W. and Kleidorfer, M. (2017) "Comparison of Multi-Criteria Decision Support Methods for Integrated Rehabilitation Prioritization”, Water, Vol. 9(68).

Wang. J.J., Jing, Y.Y. and Zhang, C.F. (2010) "Review on multicriteria decision analysis aid in sustainable energy decision-making”, Renewable and Sustainable Energy Reviews, Vol. 13, pp. 2263-2278.

Wolters, W. and Mareschal, B. (1995). "Novel types of sensitivity analysis for additive MCDM methods", EJOR, 81, pp. $281-290$.

Xiaohann, Y., Zeshui, X. and Ying, M. (2013) "Prioritized Multi-Criteria Decision Making Based on the Idea of PROMETHEE”, Procedia Computer Science, Vol. 17, pp. 449 - 456. 